\title{
Association between iron (Fe) and particulate organic matter (POM): sorption and redox buffering

\author{
PRACHI JOSHI ${ }^{1}$, DENNIS SAWWA ${ }^{2}$ AND ANDREAS
} KAPPLER $^{1}$ \\ ${ }^{1}$ University of Tuebingen \\ ${ }^{2}$ University of Tübingen \\ Presenting Author: prachi.joshi@uni-tuebingen.de
}

The biogeochemical cycles of iron and carbon are tightly coupled in soils and sediments. A large fraction (20-40\%) of soil organic carbon (in the form of natural organic matter (NOM)) is hypothesized to be protected from microbial decomposition and subsequent release as $\mathrm{CO}_{2}$ by association with iron $(\mathrm{Fe})$ species. This association may be in the form of sorption or coprecipitation with iron $(\mathrm{Fe})$-bearing minerals or complexation with dissolved Fe. Additionally, association with organic carbon may protect the reduced form of iron (Fe(II)) from oxidation to $\mathrm{Fe}(\mathrm{III})$, resulting in higher concentrations of $\mathrm{Fe}(\mathrm{II})$ in oxic systems than thermodynamically predicted. This interaction between Fe and NOM controls the stability of terrestrial organic carbon, bioavailability of $\mathrm{Fe}(\mathrm{II})$ and $\mathrm{Fe}(\mathrm{III})$, and pollutant reduction coupled to $\mathrm{Fe}(\mathrm{II})$. While interactions between $\mathrm{Fe}$ and dissolved organic matter (DOM) have been studied extensively, $\mathrm{Fe}$ - particulate organic matter (POM) interfacial processes are largely unknown. This knowledge gap is critical given that the majority of organic carbon is in particulate form and POM is composed of chemical functional groups that are different from those in DOM.

This project investigates reactions between iron (Fe(II) and $\mathrm{Fe}(\mathrm{III})$ ) with particulate organic matter (POM). To discern whether the reactivity of these Fe-POM phases is dependent upon the functional group composition within POM, we conducted experiments using peat POM sourced from bogs and IHSS peat POM sourced from marshes. We first synthesized FePOM phases via different formation pathways and determined the Fe content and speciation. We then exposed these phases to alternating oxidizing and reducing conditions that are representative of subsurface environments. Over the course of redox cycles, we quantified $\mathrm{Fe}$ speciation and release and determined the mineralogy of the reaction products. The results of this work provide insight into the stability of $\mathrm{Fe}-\mathrm{OM}$ phases in the environment, ultimately improving our understanding of organic carbon and iron biogeochemical cycling. 